\title{
PINTAR LA PROPIA ALDEA. EL TRATAMIENTO DEL ESPACIO EN LA DEUDA INTERNA (1988) Y LA ÚLTIMA SIEMBRA (1991)
}

\author{
To paint one's own village. Treatment of space in La deuda interna (1988) and \\ la última siembra (1991)
}

Jorge Sala*

https://orcid.org/0000-0002-3245-9137

\section{Resumen}

Los films de Miguel Pereira inauguran la producción ficcional cinematográfica en la provincia de Jujuy. Realizados durante la transición democrática, sus primeros largometrajes construyen una mirada particular que logra unificar las temáticas locales, vinculadas, en su caso, al entorno rural y andino, con problemáticas propias de la política y la historia nacionales. El artículo se propone analizar el modo de construcción del espacio en La deuda interna y La última siembra, entendiendo que en ellos se entretejen apuestas por la consolidación de unos rasgos locales y el modo en que estos juegan (chocan, dialogan) con ese otro lugar representado por la nación (construida, en gran medida, como un fuera de campo, pero cuya incidencia resulta crucial). Se buscará, asimismo, establecer comparaciones entre ambas obras, en función de encontrar continuidades y transformaciones.

$$
<\text { Cine Salteño }><\text { Transición democrática }><\text { Cine regional }>
$$

\begin{abstract}
Miguel Pereira's works inaugurate the fictional cinematographic production in Jujuy. Made during the democratic transition in Argentina, his first feature films construct a particular look that manages to unify local themes, related to rural and Andean environment, with problems of national politics and history. The article aims to analyze the mode of construction of the space in The debt and The Last Sowing, understanding that they intertwine bets for the consolidation of some local features and the manner in which they interact (collide, dialogue) with that other place represented by the nation (constructed as an off camera space, but whose incidence is crucial). This work will also seek to make comparisons between both films, in order to find continuities and transformations.
\end{abstract}

$<$ Argentine Cinema $><$ Democratic transition $><$ Space $><$ Regional cinema $>$

Recibido: 28/09/2020//Aceptado: 25/11/2020

\footnotetext{
* Consejo Nacional de Investigaciones Científicas y Técnicas (CONICET) - Universidad Nacional de las Artes (UNA), Argentina, jorgesala@filo.uba.ar
} 


\section{Introducción}

"Pinta tu aldea y pintarás el mundo". La frase de León Tolstoi, tantas veces repetida, resuena como un mantra adjudicable a todo creador decidido a afrontar las relaciones siempre problemáticas entre lo singular y lo general, o, más exactamente, entre lo propio conocido y lo ajeno a lo que se busca, en cierto modo, interpelar. Sin desmerecer la importancia de aquellas dicotomías evidentes, cabría preguntarse también ¿por qué un escritor acude a una noción tomada de la plástica en lugar de valerse de otro término propio de su métier como podría ser "describir"? Con toda seguridad se trata de una simple figura poética, pero su impertinencia habilita arriesgar otra hipótesis que apunta en una dirección más profunda: hablar de pintura, de signos iconográficos y no ya de la letra abstracta, pone el acento en el carácter eminentemente visual que conlleva toda referencia al terruño. Como si el poder de autoafirmación se asentara sobre dispositivos arraigados, justamente, en el "color local", para emplear otra metáfora coherente con el pictorialismo tolstoiano.

Entre los recursos posibles para formular una construcción identitaria cualquiera, la apelación a paisajes y lugares característicos, al igual que el uso de un determinado argot o de acentos singulares, devienen temas especialmente fructíferos al momento de subrayar las marcas de reconocimientos de una cultura local o regional en las obras artísticas. Pero, a diferencia del lenguaje, las imágenes relacionadas con el espacio poseen la ventaja de proveer estímulos sensoriales que no necesitan atravesar los vaivenes de la traducción para tornarse asimilables y, por qué no también, atractivas para unos espectadores externos. A su vez, estas condensan núcleos dramáticos relativos a las relaciones sociales, a la disposición de los cuerpos y a los vínculos de los sujetos con el entorno. El espacio, como ya fue definido, entre otros, por Lefebvre (2013 [1974]) es depositario de una historia, es decir, de un tiempo y de un devenir. El paisaje, en consecuencia, nunca es exclusivamente deslumbrante o inocente sino, como sugiere Andermann (2008, p. 2), "es uno de los nodos principales a través de los cuales podemos pensar la intersección entre prácticas políticas y estéticas de la modernidad, prácticas del Estado, así como de su contestación por parte de disidencias de cuño 'revolucionario' o 'conservador"'. Y no menos importante, sus mecanismos de inscripción, alusión o elusión son claves dentro del desarrollo de cualquier programa ideológico dentro del cine narrativo.

En diferentes declaraciones, el realizador jujeño Miguel Pereira puso de manifiesto un especial interés por pintar la propia aldea, como estrategia de diferenciación, dentro del campo cinematográfico de la transición democrática. En una entrevista publicada con anterioridad al estreno de La deuda interna, su ópera prima, manifestó: “¿Cómo podríamos pensar en venderles computadoras a los japoneses? Las hacen mejores y más baratas. Pero un poncho de vicuña sí les vendemos, porque no tienen vicuñas ni les convendría aprender a tejer. Nosotros nos propusimos hacer películas y venderlas afuera, pero la idea que presidió el plan fue exactamente esa. ${ }^{1}$ Asimismo, en otro reportaje posterior Pereira confirma la hipótesis referida a la pregnancia de su lugar de origen en su cine: "Yo nací y me crie en Jujuy, un lugar donde el contacto con

S/F. "De Jujuy a Buenos Aires vía Berlín”. Clarín, Suplemento de Espectáculos, 1. (1988, julio 16) 
un paisaje muy fuerte nos hace sentir, al mismo tiempo, muy libres y muy apegados a la tierra". ¿En qué consisten, por lo tanto, esos rasgos autóctonos desplegados en sus primeros largometrajes? ¿a partir de qué mecanismos de inscripción del espacio se materializa un diálogo entre lo local y lo foráneo? Por otro lado, y con relación a lo anterior: ¿de qué manera aquellos signos se articulan alrededor del tratamiento visual y cómo este permite arrojar una respuesta original tanto a la pregunta por la identidad como a aquella referida al contexto histórico político?

Tanto La deuda interna como su segundo trabajo — La última siembracomparten una idéntica pulsión topofílica, que las congrega como si se tratara de un díptico cuyas caras responden a un mismo eje. En los largometrajes iniciales de Pereira, el paisaje y los espacios habitados conforman unos elementos de los que se vale la puesta en escena para ordenar, a partir de diversos repertorios, sus recorridos narrativos. En ambos, los emplazamientos seleccionados no operan únicamente como mero soporte de las acciones; por el contrario, estas películas revelan el modo en que las locaciones asumen un carácter fuertemente alegórico y simbólico que organiza, a su vez, un discurso que acentúa los rasgos provistos por la trama. A partir de la inscripción del espacio como un problema nodal, el cineasta formula entonaciones sobre lo propio y lo extraño en función de dos perspectivas centrales: la primera apunta a situarse como una visión singular sobre el pasado dictatorial inmediatamente anterior, con los consecuentes engarces entre la política nacional y su adopción a escala local, así como las consecuencias y las singularidades propiciadas por el nuevo contexto. La siguiente, por su parte, adopta los preceptos del drama de la tierra nutrido a partir de la tradición de films rurales basados en conflictos de orden social y económico (Lusnich, 2007), núcleo a partir del cual se erige como un ejemplar tardío. Más allá de las particularidades de cada uno de los films — que se revisarán a continuación — interesa ver también la forma en que, al ser analizados en conjunto, surgen varios procedimientos unificadores y rasgos que plantean, además de la poética autoral de un cineasta, el modo en que este encara la cuestión topográfica para sentar posiciones relativas a la identidad jujeña y a su posible reificación audiovisual.

\section{El otro lugar de la Historia}

La deuda interna selló el acta de nacimiento de la producción audiovisual jujeña. ${ }^{3}$ Con anterioridad, la provincia ya había sido escenario de filmaciones de diverso tipo. Durante la década del sesenta se rodaron algunas producciones como los cortometrajes de Jorge Prelorán: Casabindo (1965), Hermógenes Cayo (imaginero) (1967), Chucalesna (1968), Señalada en Juella (1968) y otros. Precediendo a estas incursiones documentales, La Quiaca y los cañaverales de las yungas orientales

2 Gilio, Ma. E. "Estoy condenado a hacer un cine marginal. Conversación con Miguel Pereira”. Página 12. (1999, enero 04)

3 En realidad, la película estuvo precedida por el documental Eco sobre los andes (1982) co-dirigido por Miguel Pereira y Federico Urioste. Sin embargo, esta primera incursión audiovisual no tuvo una circulación comercial, por lo que el siguiente largometraje, ya en solitario, aparece como el inicio de la producción de este autor. 
sirvieron también como escenario para el rodaje de Zafra (1959, Lucas Demare), un melodrama rural en el que las desventuras sociales y amorosas de dos coyas puneños eran interpretadas, en un forzamiento de los criterios de verosimilitud, nada menos que por Graciela Borges y Alfredo Alcón. Miguel Pereira recoge el antecedente de Prelorán en su cine, del que se declara como una suerte de heredero, sobre todo en la inclinación común por lo etnográfico. No obstante, aun cuando en algunos tramos de sus obras prevalece una voluntad de registro de ciertas prácticas populares, Pereira opta por la ficción para poder, en sus palabras, "relacionarse con el público a través de emociones". ${ }^{4}$

La necesidad de mostrar una realidad, con escasa visibilidad dentro de la producción nacional, y el deseo de construir una propuesta que pudiera alcanzar al gran público, hicieron que en su primera incursión en este terreno adoptara los rasgos del cine testimonial en boga durante los ochenta. A partir de las vivencias relatadas por el maestro rural y escritor Fortunato Ramos, el director ideó un relato en el que varios acontecimientos experimentados durante el último gobierno militar se situaban en una zona de la que se sabía muy poco en términos audiovisuales, más allá de las notas pintoresquistas, etnográficas o de exotismo cultural de antaño. Profundizando la opción por arraigarse en las particularidades locales, Pereira convocó a intérpretes del elenco vocacional Nuevo teatro de la provincia, sumando como integrante externo a Juan José Camero, único actor profesional dentro del equipo. Filmada mayoritariamente en Chorcán, un pueblo del altiplano a 4000 metros de altura sobre el nivel del mar, la película edifica su relato alrededor del encuentro entre un maestro foráneo y un joven habitante del lugar, Veronico Cruz (Gonzalo Morales). Entre ambos se establece un vínculo paterno-filial y de aprendizaje mutuo que posibilita la amalgama de dos puntos de vista sobre los que se asienta la vertebración del relato. Emparentada con otro film previo de características similares — Shunko (1962, Lautaro Murúa) — La deuda interna incorpora la novedad de interpelar desde la periferia varias de las acciones acometidas por el último gobierno militar: la desaparición de personas, la prohibición de libros, los interrogatorios violentos, la persecución y, finalmente, la guerra de Malvinas.

El trabajo sobre la Historia reciente, a partir de un espacio habitualmente ignorado, fue una de las razones que ayudaron a su triunfo tras su paso por el festival de cine de Berlín, en donde obtuvo el Oso de Plata. El premio a su "destacada contribución artística" estuvo justificado por su capacidad de "meter sus dedos en las heridas abiertas de la sociedad argentina" (Bierle, 2010, p. 351, traducción propia). En un momento de auge de las ficciones testimoniales sobre el pasado inmediato - debido a la repercusión internacional obtenida por películas como La historia oficial (1985, Luis Puenzo) o El exilio de Gardel (1985, Pino Solanas) - se volvía sobre este tema, pero abriendo una hendija sobre una realidad que, hasta el momento, no había tenido cabida dentro de aquellos relatos. Lo novedoso, en gran medida, se basaba justamente en la decisión de apartarse de los entornos urbanos, tantas veces transitados por el cine de la época. En este sentido, el título brinda ya unas pistas sobre el cambio de perspectiva. En un

${ }^{4}$ L.B. "Hacer esta película fue cumplir el mandato de mi padre". La Prensa, sección Espectáculos, 3. (1991, junio 10) 
contexto de discusión sobre las implicancias de la deuda externa en el país, el director acentúa la necesidad de una mirada hacia adentro. No se trata exclusivamente de un juego de palabras o de una estrategia de marketing, sino también del establecimiento de un límite, de una frontera que apunta a traducir la distancia inexorable entre lo propio y lo ajeno. Entonces, si el pasado reciente ya fue contado desde el punto de vista de Buenos Aires, aquí se propone ver qué impacto tuvieron los hechos en esa zona ignorada que no tuvo un margen de representación dentro de los discursos dominantes o, en otras palabras, dentro de cierta "historia oficial" mostrada por el cine de la época.

Narrar el pasado modificando el punto de vista geográfico dominante implica, necesariamente, establecer un contrapunto. De ahí la importancia que adquiere en la película la conformación de dos emplazamientos antitéticos: el campo y la ciudad. En distintos momentos, La deuda interna toma partido en contra de la configuración idealizada de lo rural. Más allá de que en su factura haya primado deliberadamente un uso preciosista de la fotografía, que remarca la amplitud de la puna jujeña o el contraste entre la aridez ocre del suelo respecto del cielo azul. Esta construcción social del espacio deja entrever, desde la primera escena, su carácter conflictivo. La secuencia de apertura construye, a la manera de un prólogo, la presentación de uno de los problemas clave que atravesará los restantes aspectos de la trama: la pobreza, la postergación y lo inalcanzable que resulta para los habitantes de Chorcán el acceso a los beneficios de la modernidad. La imagen de la madre de Veronico muriendo durante el parto por carecer de asistencia médica o la siguiente en la que el padre migra a las zonas bajas, a la zafra, porque "esto ya no rinde" tocando la tierra yerma, condensan una toma de posición. Bajo esta premisa, el pueblo, lejos de cualquier atisbo bucólico, está atravesado por los desmanes causados por la pobreza endémica. Según Williams (2005, p. 75), la visión del campo como un entorno apacible se obtiene a partir de la eliminación del trabajo y de los conflictos de poder subyacentes. En esta escena inaugural, la pregnancia de la miseria marca el tono de denuncia establecido por el film y su necesidad de hallar otro destino para la representación de lo rural.

Si bien los cerros y las casas desperdigadas del altiplano ocupan el centro de los encuadres en la mayor parte del metraje, la emergencia de los acontecimientos políticos pretéritos se activa en la medida en que se alude a los centros urbanos o, más específicamente, a aquellos lugares en los que se tejen los designios del Estado. Pero ¿cómo actualizar cinematográficamente un espacio que para esas zonas olvidadas significó desde siempre una representación elusiva? Una opción sería la del empleo del montaje paralelo, dado que este recurso propiciaría con facilidad la exposición de las diferencias estructurales entre los ámbitos. Pereira opta, en cambio, por otra estrategia: a la dicotomía, tantas veces visitada que separa lo rural de lo urbano, se le adosa una segunda polaridad fundante de las operaciones de puesta en escena fílmicas. Esta es aquella tendiente a plantear las tensiones narrativas y estilísticas entre el campo y el fuera de campo. Como recuerda Pascal Bonitzer (2007, p. 68), en el cine la pantalla es una visión parcial que separa aquello que efectivamente se nos es revelado de ese lugar (al que denomina campo ciego), al cual solo se accede en ocasiones puntuales. De 
esta manera, mientras Chorcán aparece como un centro, no solo narrativo sino también visualmente irradiador, la urbe politizada que dirige los destinos públicos llega a la pantalla mediante sus reverberaciones lejanas o, mejor dicho, a partir de sus efectos devastadores.

Entendida como visión parcial de una realidad mayor, la puesta en escena del pueblo maximiza la desconexión o, más exactamente, las interferencias reales que impiden un contacto efectivo con ese otro territorio que constituye el resto del país y su gobierno central. La radio, en tanto medio de comunicación que podría poner en contacto esos universos, sirve aquí, por el contrario, como un vehículo que ensancha la sensación de extrañeza de los pocos habitantes que tienen acceso a ella. El disloque existente entre los dos emplazamientos queda puesto de manifiesto a partir del viejo transistor de Domingo, uno de los pobladores con los que el maestro entabla relación. Las características geográficas del entorno hacen posible que el aparato capte transmisiones procedentes de lugares tan distantes a la realidad puneña como Brasil. Como señala Lillo (2008), la radio aquí "no conecta a la comunidad con las ondas de la modernidad homogénea de la nación, sino que abre el espacio cultural a interferencias diversas" (p. 135). De manera humorística, la sintonización de un dial que emite voces de locutores hablando en portugués grafica el aislamiento que separa al pueblo de cualquier otro lugar, convertido en una lengua imposible de traducir. A su vez, la radical desindetificación entre el territorio visible con relación a los centros de poder provoca que, cuando los pobladores escuchen el bando que anuncia la instauración del gobierno militar de 1976, este no pueda ser oído sino como una suerte de ruido más. La frase "otro golpe militar", proferida por uno de los habitantes, acentúa cierta inmutabilidad experimentada por los sujetos.

Sin embargo, la plasmación escénica de la llegada de los militares a Chorcán es mostrada como una efectiva invasión del espacio. En un lugar al que solo se accede mediante animales de carga, que carece de rutas y de otras formas más directas de comunicación, la irrupción de la camioneta camuflada aparece como una literal violencia sobre el entorno. Pereira no necesita mostrar la tortura o la muerte, sino simplemente aludir a su potencialidad mediante el choque entre dos realidades: la modernidad del vehículo y la conmoción de los animales desplazándose por el terreno. Si hasta el momento la presencia del Estado, o de la ley, asomaba como un dato menor bajo las figuras del comisionado o del oficial de policía — retratados más en sus gags cómicos que en su carácter de representantes del poder - la imagen de los militares ingresando desde ese nebuloso fuera de campo, que constituye todo lo ajeno al pueblito, trastoca definitivamente el estado de las relaciones sociales entabladas internamente. 
Figura 1. El vehículo militar ingresando al pueblo de Chorcán.

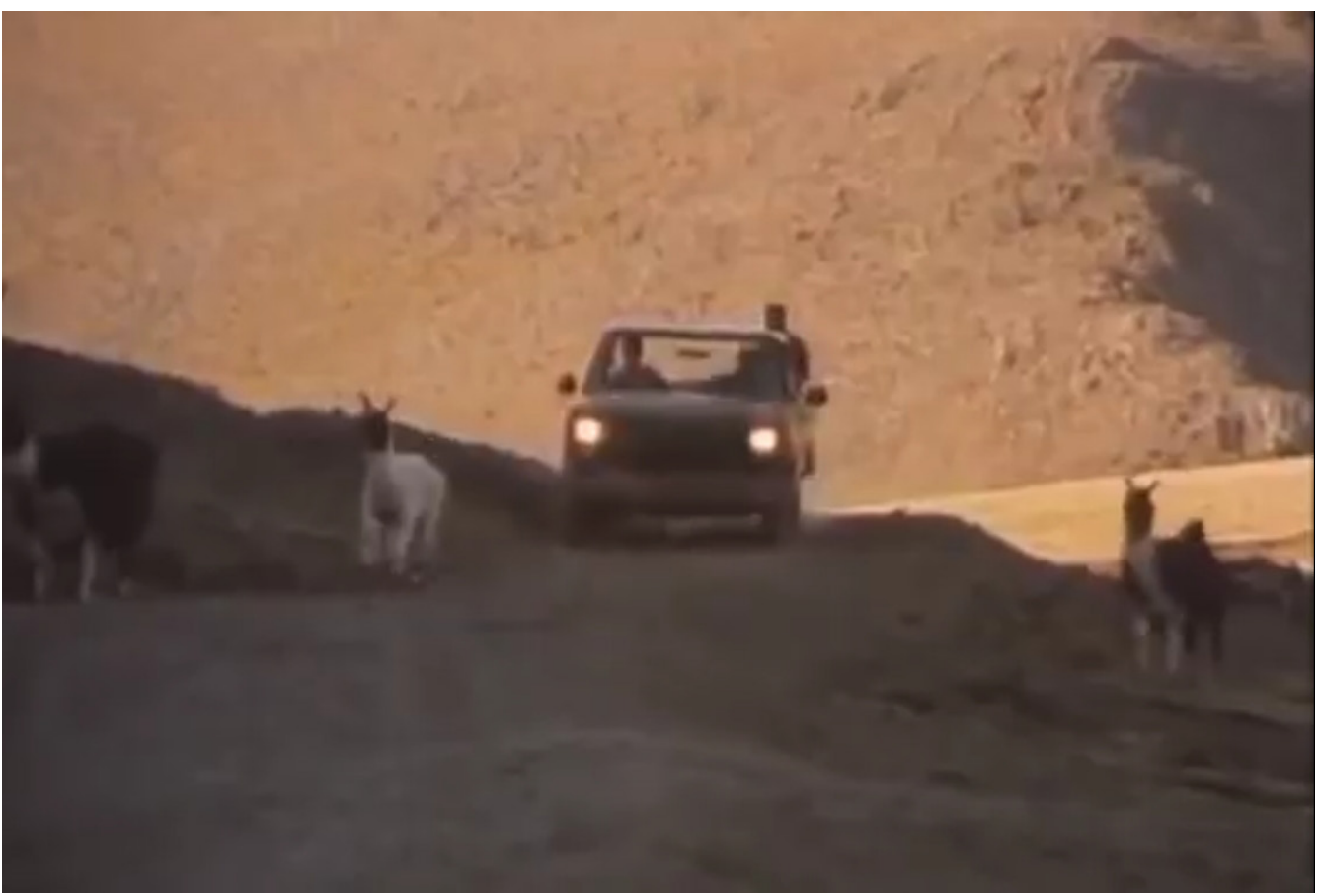

En la figuración de la violencia identificada como una amenaza proveniente del exterior subyace una lógica análoga a la del cine testimonial hegemónico de los ochenta, cuyo exponente clave es La historia oficial. La reacción de los pobladores, al recibir la llegada de los militares a Chorcán, los sitúa en la posición de víctimas inocentes de las disputas políticas. Al igual que el personaje de Norma Aleandro en la película de Puenzo, aquí la no participación de los habitantes en las vicisitudes nacionales prohijadas más allá del lugar, muy lejos del territorio conocido, remarca su condición de ajenidad frente al conflicto. Por otra parte, el hecho de que el policía del pueblo, convertido en autoridad, no sepa identificar los libros que debe secuestrar de la casa del maestro por no saber leer traduce, en cierto modo, una obediencia debida que afecta el comportamiento del oficial y de alguna manera lo exculpa de su responsabilidad frente a los hechos. Más allá de estas coincidencias, el relato construye, a partir de una carta enviada por el padre de Veronico, su derrotero como peón rural y obrero en Altos hornos Zapla, al tiempo que da cuenta de su participación política frente a la explotación. En este segmento, el espacio se transforma dando paso por primera vez a otros territorios. Se pasa así de la aridez, que dominó hasta entonces la banda visual, al verde de los cañaverales de las yungas y a la tonalidad sombría de las fábricas.

Aun cuando el régimen de visibilidad dominante en la película tiende a remarcar la distancia infranqueable respecto de lo urbano, hay toda una secuencia en la que sus protagonistas se trasladan a San Salvador de Jujuy para obtener información sobre el paradero del padre de Veronico. Con el telón de fondo del abigarramiento de automóviles 
y carteles luminosos que anuncian diversos negocios, la imagen de la ciudad se hace presente, esta vez sí, de manera contrastiva.

Figura 2. La ciudad abigarrada.

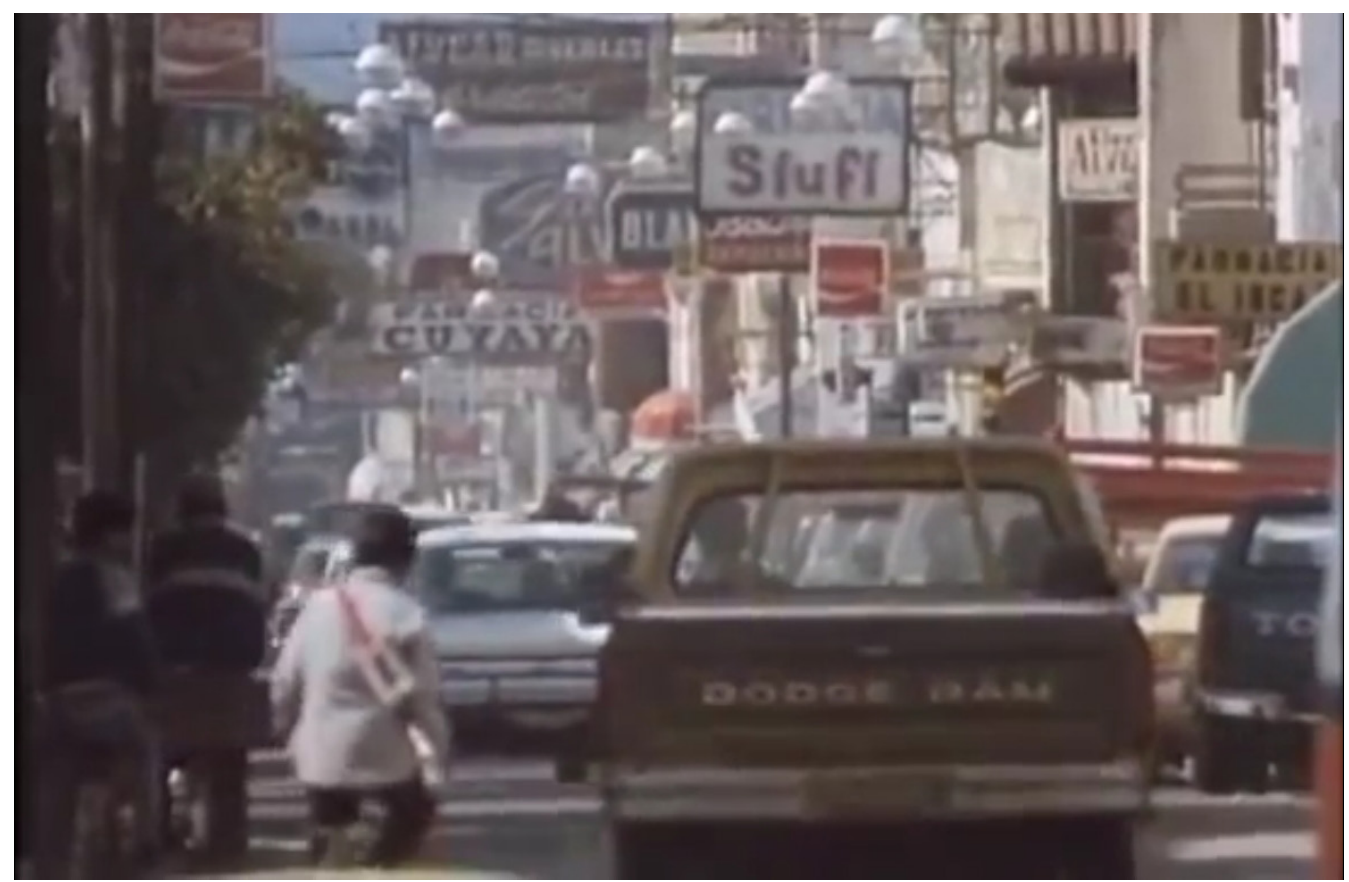

El núcleo de la secuencia transcurre en la plaza Belgrano, en el centro histórico de la provincia, con el monumento ecuestre del prócer en el centro del plano. En este punto, el maestro y Veronico se separan momentáneamente. La puesta en escena establece, en consonancia, una bifurcación de los puntos de vista aunándolos mediante el empleo del montaje paralelo. Mientras el niño y la cámara recorren la catedral y la casa de gobierno a partir de planos subjetivos, el maestro participa de un interrogatorio por parte de las fuerzas del orden. Reflexionando sobre la participación del mundo infantil en las películas del cine moderno, Deleuze (1985, p. 14) propone que su presencia cobra un sentido superlativo en la medida en que estos personajes condensan cierta carencia motriz que magnifica su capacidad para mirar y oír, para descubrir el mundo desconocido. En La deuda interna, la visión obnubilada de Veronico - no solo por ser un niño sino también por ser efectivamente un completo extraño dentro del entorno urbano - se opone a la perspectiva menos celebratoria revelada por la experiencia del maestro. Si de un lado se ubican los símbolos patrios, las imágenes inertes de los santos o el Salón de la bandera de la casa de gobierno en el que yace una porción de la historia nacional, a poca distancia se materializa otra realidad: la de un gobierno militar que trastoca el nacionalismo a partir del miedo. La plaza es, en este sentido, un espacio estratégico en la representación del poder, en función de su capacidad de reunir 
tanto la mirada encandilada con el heroísmo local como aquella otra aterrorizada por la potencialidad violenta de sus efectos.

Figura 3. Veronico (Gonzalo Morales) descubriendo el centro de la ciudad.

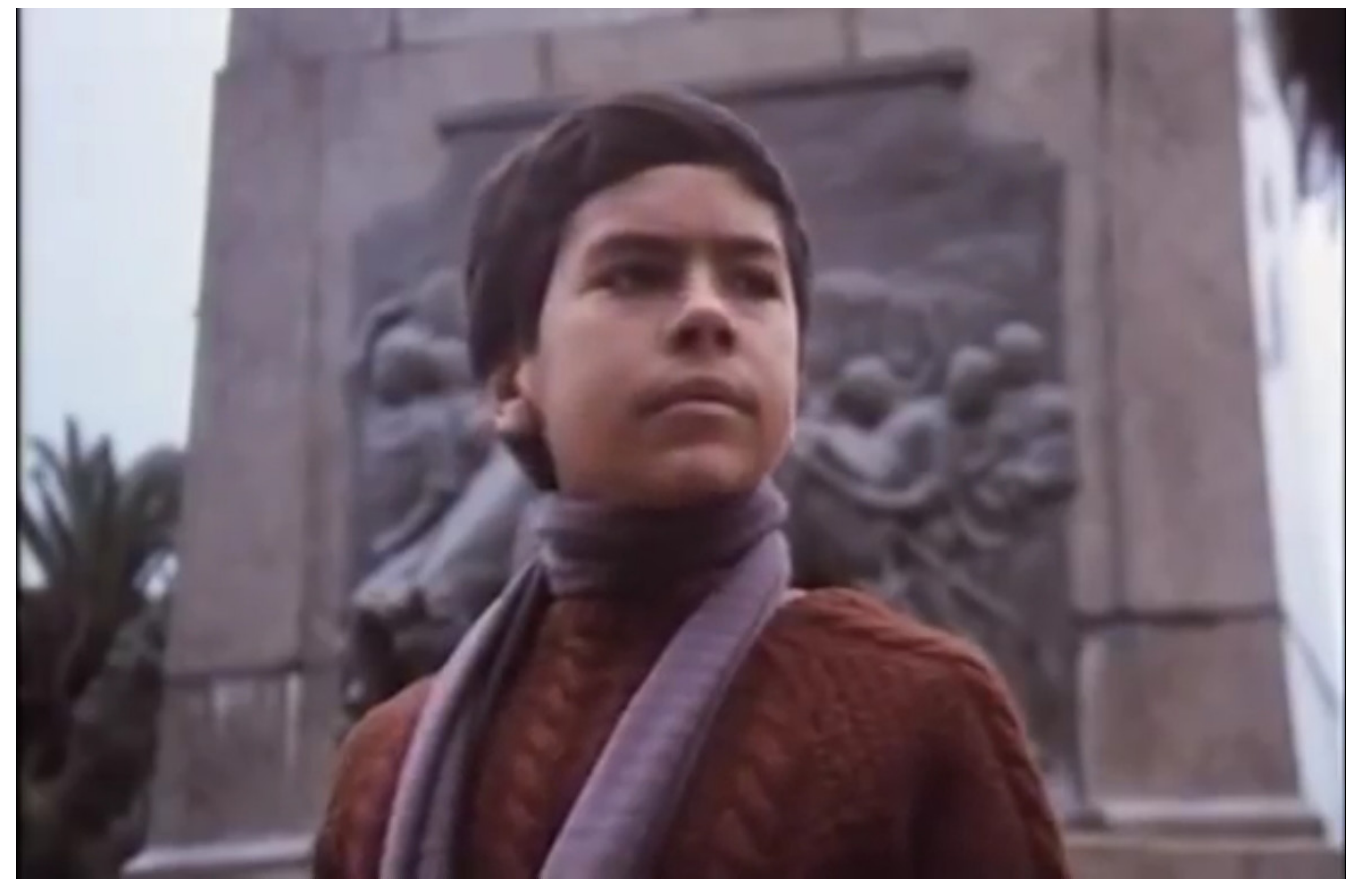

\section{La deuda con los héroes anónimos}

Mientras la ciudad y el campo son concebidos desde distintos mecanismos de visibilidad, hay un tercer espacio clave en la película identificado exclusivamente a partir de referencias laterales. El mar en el que muere Veronico, luego de participar como tripulante en el Crucero General Belgrano durante la Guerra de Malvinas es, simultáneamente, un lugar fantasmático y omnipresente debido a sus constantes menciones. En términos geográficos, el mar se ubica en las antípodas de la aridez del altiplano, recortándose como un ámbito inalcanzable por antonomasia para los pobladores de Chorcán. Sin embargo, ciertas alusiones golpean con insistencia a lo largo del relato, movilizando las fantasías de ese niño que está descubriendo nuevas formas de asir el mundo que lo rodea. Las historietas sobre piratas ingleses que el maestro le regala en su primer encuentro, el salar convertido en huella espectral de lo marítimo, la mención a Hong Kong —al igual que Malvinas, una isla colonizada por el imperio británico - operan como indicios que sobredeterminan el devenir del desenlace trágico del protagonista. La puesta opta aquí por el uso de material de archivo, incorporado diegéticamente bajo la forma de noticias que llegan por la televisión y la radio. Los discursos del General Galtieri, las movilizaciones populares y los comentarios periodísticos sobre el avance del conflicto ayudan a anclar la narración en un referente 
de fácil reconocimiento. Entonces, si el mar y las Malvinas constituyen un campo ciego absoluto dentro del andamiaje espacial de la película, la fotografía de Veronico con traje de marinero y la frase "los changos del Belgrano" sella, bajo la forma del testimonio, justamente aquella deuda del país para con los habitantes del interior profundo, que la película configura desde su mismo título.

En los últimos tramos del film, la modificación del emplazamiento en el que se desarrollan las acciones cobra un sentido que no es en ningún modo accidental. Tras abandonar Chorcán, el maestro es reubicado en Humahuaca. Situado en el centro del pueblo, el monumento a los Héroes de la Independencia, de Ernesto Soto Avendaño, opera como un vertebrador espacial que, al mismo tiempo que brinda información sobre el lugar a partir de uno de sus enclaves inconfundibles, adquiere en la secuencia final un carácter eminentemente simbólico. El grupo escultórico, conocido vulgarmente como el "monumento al indio" por la figura central que lo preside, fue originalmente concebido como un homenaje realizado por el gobierno central al pueblo jujeño y a su papel dentro de la gesta independendista. Según Fasce (2017), este "proponía una lectura de la historia nacional que simpatizaba con los sectores populares: no hay un prócer ni una figura histórica reconocible, sino que sus protagonistas son gauchos e indios de origen humilde" (p. 207). La recepción de la obra de Soto Avendaño atravesó, de acuerdo con Fasce, distintos contextos: tanto aquellos vinculados a la vertiente nacionalista del centenario como los que fueron propiciados por la recuperación de ciertas figuras realizadas por el primer peronismo. Pereira adosa a estas interpretaciones una nueva, acorde con su propio programa estético y narrativo. En el film, el desarrollo del conflicto bélico está acompañado por la puntuación de diversos planos detalle del monumento. En estas imágenes-emblema, de enorme densidad simbólica, surgen hombres y mujeres valerosos, aguerridos, enfrentándose a un enemigo externo. Mediante el juego de superposiciones con las imágenes de archivo, el espectador de la película podría situar al Veronico combatiente - representado por una fotografía idéntica en su inmovilidad a la de que aquellas desplegadas por el bronce de la escultura - dentro de este grupo caracterizado por su heroísmo anónimo frente a los cimbronazos de la historia nacional. 
Figura 4. Monumento a los Héroes de la Independencia, en el centro de Humahuaca.

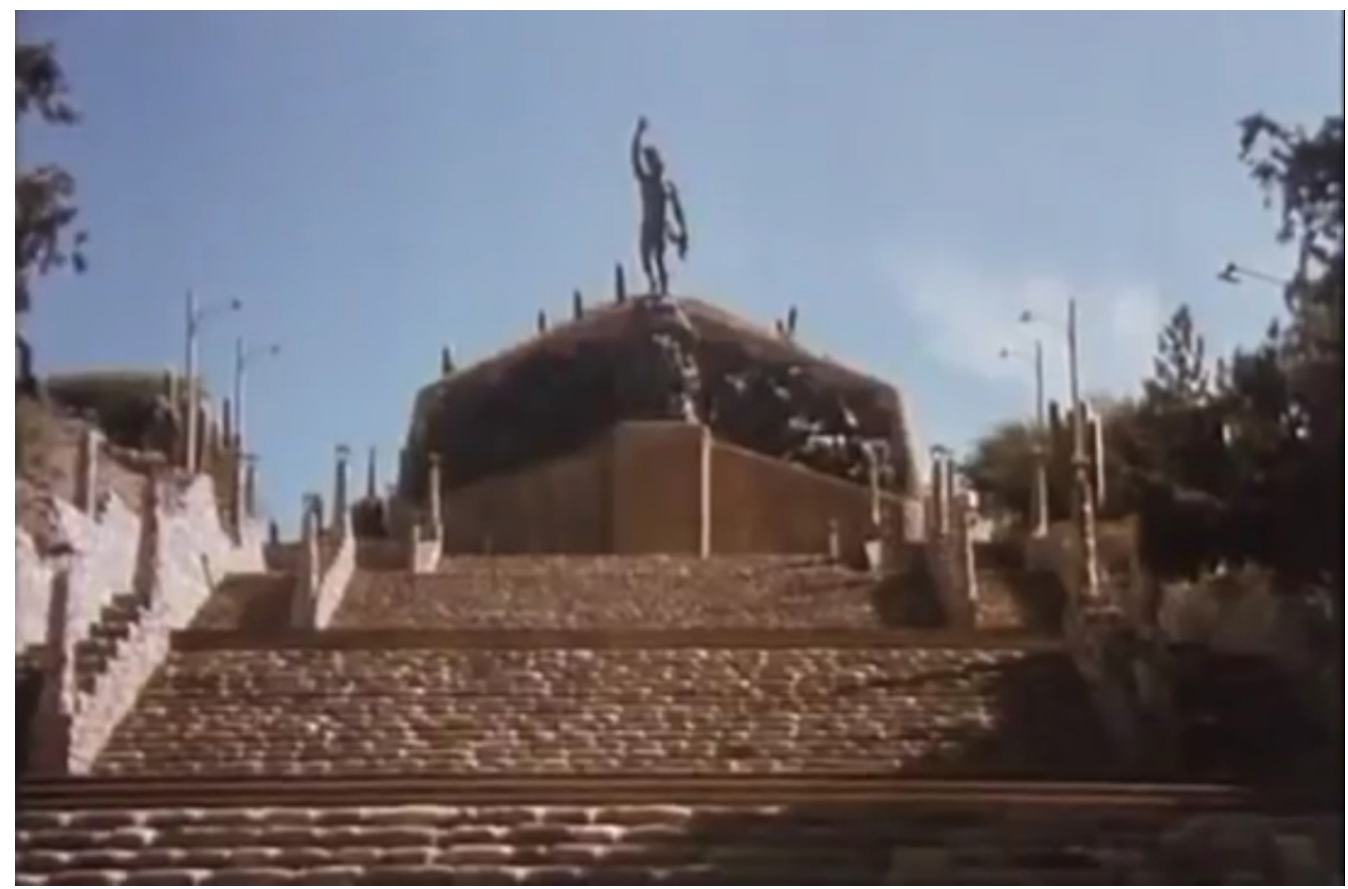

Como pudo verse, el tratamiento del espacio en la película opera sobre dos vertientes complementarias: construyendo, por una parte, unos emplazamientos reconocibles a través de los cuales la puesta en escena se sirve para anclar la ficción, según los postulados de un programa asociado con el realismo testimonial imperante en la transición democrática. En segundo lugar, aunque no menos importante, la elección de determinados ambientes o, por el contrario, la decisión de eludirlos visualmente (sobre todo al momento de referirse a las zonas alejadas de la provincia) asumen un matiz claramente alegórico que trasciende el mero registro realista o documentalizante. En un doble movimiento, tanto de autorrepresentación de lo local como de señalamiento de las diferencias con aquello que se ubica por fuera del territorio - al igual que en el imperativo por exhibir sus tensiones inherentes - se funda el interés de Miguel Pereira por construir un cine desde y sobre Jujuy. Profundizando estas coordenadas, su segundo largometraje abrirá nuevos horizontes en la construcción de autoimágenes. Al igual que en La deuda interna, aquí también surgirán distintas declinaciones audiovisuales que tuvieron como centro irradiador los modos de encuadrar el espacio y sus vicisitudes dentro de esta particular modalidad de conformación de un cine regional.

\section{Lo viejo y lo nuevo}

Retomando varios episodios de Los humildes, libro de relatos escrito por su padre, Miguel Ángel Pereira (1967), el cineasta emprendió la construcción de la trama 
de La última siembra. El espaldarazo internacional obtenido por su ópera prima, ${ }^{5}$ al igual que el alcance masivo recibido en su paso por la cartelera local hicieron que esta producción pudiera contar con varios actores reconocidos: Patricio Contreras, Leonor Manso, Mario Pasik y Alberto Benegas formaron parte del equipo. Al igual que en la anterior, varios intérpretes de teatro locales se sumaron al elenco: nuevamente Gonzalo Morales, ocupando uno de los papeles principales junto a otros nombres como los de Edmundo Asfora, Damián "Tito" Guerra y el escritor y político jujeño Antonio Paleari, en el rol del patriarca dueño de la estancia "La Almona" donde se despliegan las acciones.

Según se mencionó al principio, esta segunda incursión en el cine de ficción detenta algunos rasgos familiares con los dramas social-folclóricos articulados en torno a la exposición de conflictos económicos y políticos. En este sentido, ciertas pautas del tratamiento espacial permiten situarlo como una variante tardía afincada, a diferencia de aquellos, en la actualidad y no en un pasado distante. Continuando ciertas premisas provistas por aquel modelo, La última siembra se desarrolla a través de una concentración de las acciones en una locación única convertida en escenario de las disputas entre dos sectores antagónicos.

Con relación a su trabajo previo, hay aquí un cambio radical del entorno. Según Pereira, "[s]e modifica la geografía, que para mí no es un telón de fondo, sino parte esencial del drama del hombre (es en este sentido que afirmo que las imágenes pueden reemplazar a las palabras). De la puna nos desplazamos a los valles templados, a una zona subtropical que no se suele relacionar con mi provincia" (García Olivieri, 1998 , p. 2). La relocalización implica, más allá de una transformación en el trabajo con las coordenadas topográficas, una modificación considerable en lo que respecta a las situaciones que allí se dan cita. En la búsqueda por construir una identidad local a partir de la representación de sus espacios característicos y de los sujetos que lo habitan, Pereira establece un giro en el que profundiza la mostración de unos lugares con escasa visibilidad dentro de la cultura audiovisual existente hasta el momento.

A diferencia de su ópera prima, en la que los datos relativos al espacio se identificaban de manera inequívoca en función de su inclinación a un tipo de registro testimonial, aquí las posibilidades de reconocimiento se tornan más ambiguas. El lugar de las acciones carece, en consecuencia, de unas coordenadas topográficas precisas, más allá de aquellas aportadas por ciertos emplazamientos como son los del casco de estancia, la iglesia y otros sitios comunes a cualquier finca de ciertas dimensiones. La voluntad de no construir una relación deíctica entre la imagen y su referente real produce, al mismo tiempo que la carencia de un anclaje específico, la posibilidad de asimilar la ficción a otros territorios. Ambas cuestiones redundan en la potencialidad del relato de establecer una lectura de tipo general. "La Almona" es parte de un territorio imaginario identificado con Jujuy — sobre todo por algunos elementos que se verán a continuación- $\mathrm{y}$, al mismo tiempo, podría ser otro lugar del país o de América en el que se experimenten situaciones análogas.

5 Más allá del Oso de Plata obtenido en Berlín y de otros lauros en festivales internacionales, la película fue seleccionada para representar a Argentina en la pre-candidatura a los Oscars y a los Globos de Oro. 
Aunque la apuesta estética en este caso esté signada por la búsqueda de la revelación de un entorno novedoso y, como consecuencia de ello, por la exposición de las contradicciones internas de una manera original con relación a la de su film anterior, hay todavía algún punto de contacto que permite pensar a ambas propuestas como integrantes de un mismo entramado autoral. La última siembra se inicia con el viaje de Chauqui (Contreras), un minero puneño que abandona el altiplano luego de la muerte de su hijo para afincarse en las tierras bajas, dentro de la finca comandada por Don Carlos. Hay en esta elección un movimiento que es, al mismo tiempo, una reiteración de motivos narrativos e iconográficos como su variación propiciada por el nuevo contexto. La historia de Chauqui podría interpretarse, con las diferencias del caso, como la narración del periplo de Cástulo Cruz, el padre de Veronico, obligado a migrar a los valles para emplearse en la zafra. Aquello que en La deuda interna había quedado solamente aludido lateralmente, juega un rol central en tanto marca el encuentro hostil experimentado por un habitante de las zonas andinas con aquellos lugares económicamente más productivos.

El traslado del protagonista, contado en los primeros minutos, funciona de manera similar al recorrido de los héroes de algunos dramas sociales del cine clásico local -Prisioneros de la tierra (1939, Mario Soffici) y Las aguas bajan turbias (1952, Hugo del Carril), concretamente - en el que el ingreso a un espacio diferente les permite una toma de consciencia mayor acerca de unas condiciones de explotación fuertemente arraigadas. A su vez, en el film de Pereira el movimiento hacia un nuevo territorio ayuda a abrir el camino para la inclusión de otros sujetos característicos, que amplifican el repertorio cinematográfico que se tenía sobre los habitantes de Jujuy hasta el momento. La llegada a "La Almona" describe los mecanismos de patronazgo semifeudal representados por la figura de Don Carlos y, al mismo tiempo, habilita la aparición de otros personajes que también constituyen parte de la identidad local, aunque esta haya sido históricamente obliterada dentro del imaginario audiovisual sobre la provincia. Por contraposición a Chauqui y sus costumbres ancestrales, vinculadas con su procedencia indígena, surge la figura del gaucho Julián (Benegas): un hombre a caballo que oficia de capataz de la hacienda. Entre ambos personajes, provenientes no solo de culturas disímiles sino también de modos divergentes de asumir la relación con la tierra y el entorno, se establece una antinomia que marca uno de los conflictos iniciales del drama.

En la primera parte, Pereira describe las relaciones sociales y para ello se sirve del paisaje como un elemento clave. La amplitud de horizonte de las tierras bajas y el uso de una paleta en la que los matices de verde (opuesto al ocre de La deuda interna) estructuran las decisiones de puesta en escena. En el microcosmos construido al interior de la finca, la llegada de Chauqui establecerá una tensión fundante entre dos formas de producción en cierto modo antinómicas: mientras el cultivo del maíz determina la práctica de subsistencia principal para el indio, con la exhibición de los rituales a la tierra que el film se encarga de exponer, este producirá un cortocircuito con la ganadería que predomina en el lugar y que tendrá en Julián a su principal exponente. "Las vacas no comen maíz", argumenta el último, para marcar la imposibilidad de convivencia de 
ambas prácticas en un mismo territorio. En estos primeros tramos, la postura ideológica construida por la película opta por no establecer una mirada crítica en torno de los mecanismos de explotación de los peones rurales, aunque no por ello deje de brindar un testimonio acerca de algunos de sus rasgos problemáticos. No obstante, la tensión entre el gaucho y el indio tenderá a disiparse progresivamente, en la medida en que surge otro elemento que articulará un nuevo quiebre dramático en el desarrollo narrativo.

Mientras su ópera prima construía una polaridad explícita entre la ciudad y el campo a partir del juego entre lo visible y lo aludido/enunciado, aquí esta tensión toma la forma de un antagonismo mayor que confronta las formas de producción históricamente arraigadas, frente a la invasión provocada por las nuevas estrategias económicas vinculadas a la tierra. En este sentido, la figura de Patricio (Pasik), el hijo ingeniero formado en el exterior que retorna a la hacienda buscando reemplazar la ganadería por la plantación a gran escala de tabaco de exportación, constituye el núcleo principal del conflicto retratado por la película. A la contradicción en términos espaciales se impone, por lo tanto, una dicotomía relativa al tiempo. En su primera parte, el film construye un muestrario de acciones de larga data entre los pueblos campesinos de Jujuy: los rituales a la pachamama realizados por Chauqui, los espectáculos de doma de caballos, los encuentros en una proveeduría pautados por el consumo de alcohol (que recuerdan iconográficamente a otros momentos de este tipo situados en las pulperías de antaño) y los bailes folclóricos de los gauchos. En su conjunto, estas escenas remiten a un pasado tradicional remoto, pero aun así todavía activo. Por contraste, el presente queda delimitado a partir del ingreso de computadoras, de tractores que suplantan a los caballos y por los medios de comunicación que tendrán un papel determinante en el contacto con el mundo exterior convertido, aquí también, en un fuera de campo exclusivamente aludido y no actualizado en imágenes.

Al igual que la radio en La deuda interna operaba como un signo de demarcación de la enorme separación de los habitantes de Chorcán, con relación al resto del país, en La última siembra se postulan nuevas formas de construcción de la ajenidad a través de las tecnologías comunicacionales del momento. El teléfono y el fax, objetos propios de una contemporaneidad completamente extraña para la finca, cumplen la función de recibir los contactos con los inversores estadounidenses. Cuando las noticias llegan y son recibidas por Francisca (Manso), la criada de la casa, estas no pueden traducirse y, por ende, ser comprendidas para quienes serán los principales damnificados.

Es interesante notar cómo, en este punto, la puesta en escena figura la disparidad entre lo tradicional y lo novedoso-disruptivo a partir de los medios de locomoción que permiten transitar por el terreno y que, a la sazón, definen los rasgos principales de los antagonistas. El caballo constituye el implemento característico de los gauchos, en general, y de Julián específicamente. La importancia de su uso como marca de identidad de un sector queda tematizada en varios momentos del relato. Otro tanto ocurre con la bicicleta, un objeto con una historia arraigada dentro del universo rural, que aparece como el instrumento definitorio de los movimientos tanto de Chauqui, de José (Morales) y finalmente de Julián. Por contraposición a ambos, la moto en la que arriban 
a la estancia Patricio y su novia (Inés Estévez) establece el contraste, entre las formas tradicionales de atravesar el espacio con las modernas maneras de surcarlo (y, al mismo tiempo, de arrasarlo). Nuevamente aquí, al igual que lo que sucedía con el jeep de los militares en el film anterior, la conmoción visual y sonora que produce la intromisión de un moderno medio de transporte, en un entorno desacostumbrado a tales presencias, adopta la forma de una alegoría física que anticipa el quiebre narrativo que establecerá el ingreso del hijo a "La Almona".

El gesto de rebelión que propone el relato no adopta el carácter colectivo que poseían los desenlaces de los dramas clásicos, basados en la representación de conflictos de orden económico. Aquí, sin embargo, la alianza establecida entre Julián y Chauqui, en función de la asunción de un enemigo común (Patricio o, más exactamente, sus intenciones de barrer con las formas tradicionales de trabajar la tierra y de relacionamiento con el entorno), asume también una entidad épica. La escena final del enfrentamiento recuerda más a la muerte solitaria del gaucho Juan Moreira, en el film de Leonardo Favio (1971), que a los levantamientos populares del drama social. Resulta sintomático, en tal sentido, que la acción que consuma la venganza por parte de los humildes quede puntualizada a través de la destrucción de la moto de Patricio. En un contraste directo con la imagen de un caballo que ocupa una porción importante del plano, el facón hundiéndose en el asiento de cuero sintetiza las ansias de recuperación de un tiempo perdido, que el enemigo amenazante ha pretendido derribar infructuosamente.

\section{La apertura de un camino}

Frente a la pregunta cerca de su insistencia en concretar un cine desde y sobre Jujuy, Miguel Pereira esgrimía razones políticas referidas a la necesidad del registro de la cultura autóctona, de sus diversos matices. Recuperando la frase acerca de que "un país sin cine es como una casa sin espejos", el realizador respondía con una reversión de esta idea: "cuando un provinciano se mira en el espejo, se transforma en Drácula: no se refleja. Los provincianos no nos reflejamos en los pocos espejos que hay en nuestra gran casa". ${ }^{6}$ Las búsquedas de sus primeras películas, como quedó demostrado, se fundan en el afán de otorgar una carnadura específica a las imágenes expuestas en la pantalla en tanto intento de reposición de una realidad soslayada.

Según se enunció en repetidas ocasiones, el cine de la transición democrática tuvo como imperativo general el mostrar aquello que había permanecido oculto por distintas razones. Esto habilitó un arco amplio de temáticas que oscilaron entre la revaluación de los acontecimientos del pasado inmediato $\mathrm{y}$, asimismo, dio lugar en otro frente a una verdadera explosión de cuerpos desnudos, a la emergencia de una sexualidad desembozada, así como a la presencia de temas de los que se había hablado poco o prácticamente nada hasta entonces. Con sus películas, Pereira optó por otro camino. En ellas buscó correr el velo de las locaciones repetidas para exhibir unas zonas olvidadas que, hasta entonces, solo habían tenido una inscripción desde lo etnográfico

\footnotetext{
${ }^{6}$ S/F. "Los extraños caminos de la vida. Entrevista con Miguel Pereira". La Nación. (2007, agosto 20).
} 
o a través de la arbitrariedad melodramática. Su cine, al igual que otras producciones de la época -Gerónima (1986, Raúl Tosso), La película del rey (1986, Carlos Sorín) o El viaje (1990, Pino Solanas) - reveló unos paisajes desconocidos y lo hizo con la ferviente decisión de no regodearse en el gesto pintoresquista, sino atento a la necesidad de dar cuenta de sus contradicciones irresueltas en términos sociales. Es a partir de esta idea que aúna la puesta en imágenes de un espacio, sin omitir en ningún momento aquellos dilemas que lo atraviesan. Esto permite pensar en sus films como efectivas materializaciones pautadas por un deseo de expresión (fundante, como ya se mencionó) de una identidad audiovisual de tipo regional.

Las regiones geoculturales, según las define Heredia (2004), son el resultado de un intercambio dinámico entre un territorio específico y la acciones e idearios que una comunidad determinada construyen, alrededor de sí misma, y con relación a los otros. Más que entidades fijas (geográficas o históricas) las regiones y, podría agregarse, el cine regional, se articula en torno a

Espacios culturales imaginados colectivamente como escenarios en donde se despliegan identidades (prácticas y pertenencias culturales) que se reconocen comunes para la mayoría de los miembros que los habitan. Podríamos decirlo al revés ya que, en verdad, dicho sentido operativo es dialéctico: debido a que una colectividad dada despliega identidades comunes, se imaginan espacios que delimitan fronteras donde se practican dichas identidades" (Heredia, 2004, p. 103).

Los límites, aunque móviles e históricamente situados, resultan más o menos claros. Lo regional o, más específicamente, aquello que el cine pretende afirmar como parte de una identidad local, tenderá siempre a constituir una línea divisoria que estratifica lo geocultural en dos zonas: un campo interno de autorrepresentación —en términos de temas y motivos audiovisuales de reconocimiento de lo propio- $\mathrm{y}$ otro externo - en la clave de una diferenciación con aquello que es ajeno a ese territorio-. En sus primeras películas, Pereira problematiza ambas cuestiones a través de diversos mecanismos de inscripción del espacio. En tanto apuestas por la identidad — que, como pudo verse, es al mismo tiempo fuertemente arraigada en tradiciones e inestable por los asedios exteriores - sus films instauraron unos puntos de vista no solo acerca de las culturas autóctonas, sino también sobre el lugar de Jujuy dentro de la Historia política nacional o de sus movimientos económicos en términos más amplios. Pintando su propia aldea (conflictiva y, en cierto modo, trágica) sin desconocer el atractivo provocado por el exotismo visual y narrativo de sus relatos en los mercados internacionales, La deuda interna y, en menor medida, La última siembra, alcanzaron un lugar distintivo dentro del panorama cinematográfico de la transición democrática. 


\section{Referencias bibliográficas}

Andermann, J. (2008). "Paisaje: imagen, entorno, ensamble", Orbis Tertius. Revista de Teoría y Crítica literaria. 13(14), La Plata. Recuperado de: http://www.memoria. fahce.unlp.edu.ar/art revistas/pr.3749/pr.3749.pdf

Bierle, P. (2010). Die Beziehungen zwischen Deutschland und Argentinien. Berlín: Vervuert.

Bonitzer, P. (2007 [1982]). El campo ciego. Ensayos sobre el realismo en el cine. Buenos Aires: Santiago Arcos.

Buckland, W. (2019). "Orientación en el espacio fílmico. Una aproximación desde la semiótica cognitiva”. En Conde, J. A., Semiótica del cine y el audiovisual. Nuevas tendencias. Bogotá: Departamento de Humanidades, Facultad de Ciencias Sociales, Universidad de Bogotá, pp. 91-110.

Deleuze, G. (2005 [1985]). La imagen-tiempo. Estudios sobre cine 2. Barcelona: Paidós

Fasce, P. (2017). El noroeste y la institucionalización de las artes en Argentina: tránsitos, diálogos y tensiones entre región y nación (1910-1955). Buenos Aires (Tesis doctoral inédita).

García Oliveri, R. (1988) "Miguel Pereira o el secreto de vivir quemando etapas". Clarín. Sección Espectáculos. (octubre 16)

Heredia, P. (2004). “¿Existen las regiones culturales? Introducción, crítica y proyecciones de los estudios geoculturales". Silabario, 7, Ciudad de Córdoba, agosto, 103-111.

Lefebvre, H. (2013 [1974]). La producción del espacio. Madrid: Capitán Swing.

Lillo, G. (2008). "Nuevas posturas críticas en el cine argentino: La deuda interna (1987), Un lugar en el mundo (1992) e Historias mínimas (2002). Canadian Journal of Latin American and Caribbean Studies, Vol. 33, 66, 129-156.

Lusnich, A.L. (2007). El drama social folclórico. El universo rural en el cine argentino. Buenos Aires: Biblos.

Pereira, M. A. (1967). Los humildes. San Salvador de Jujuy: Edición del autor.

Williams, R. (2006). El campo y la ciudad. Buenos Aires: Paidós

\section{Artículos periodísticos}

S/F. "De Jujuy a Buenos Aires vía Berlín”. Clarín, Suplemento de Espectáculos, 1. (1988, julio 16). 